\title{
Dynamic Management and Control Strategy of Highway Engineering Cost
}

\author{
Caiyan Zhang* \\ Gannan Prefecture Transportation Bureau, Hezuo 747000, Gansu Province, China
}

*Corresponding author: Caiyan Zhang, gnjtjzcy@ 126.com

\begin{abstract}
The rapid economic development has promoted the construction of infrastructure, such as highways and water conservancy projects. The establishment of highways has facilitated people's lives and made the distance between regions shorter and shorter. However, the construction of highway engineering is a big project, which not only has a long cycle, but also has a high economic cost. During the construction process, a large number of construction materials and personnel will be applied. If the project cost management is not implemented for the highway construction, it will easily affect the final quality and profit of the entire project. This article expounds the significance of dynamic management and control of highway engineering cost, and analyzes the strategy of dynamic management and control of highway engineering cost.
\end{abstract}

Keywords: Highway; Engineering cost; Dynamic management; Control strategy

Publication date: July 2021; Online publication: July 31, 2021

\section{Introduction}

In recent years, various regions in our country have developed rapidly. In order to meet people's pursuit of a higher quality of life, the country has also begun to build a large number of highway projects to promote better social development. Due to the characteristics of the project itself, it is necessary to pay attention to the management of its project cost in the construction of highway projects. However, the cost of traditional highway engineering is inconsistent with the development of existing highway engineering, and there are many problems. For example, the awareness of the whole process of cost control is not strong, the lack of sound rules and regulations, and the quality of employees are not high. Therefore, it is necessary to strengthen the strategy of exploring highway engineering cost management to improve the quality and efficiency of highway construction.

\section{The significance of dynamic management and control of highway engineering cost}

Project cost refers to the project cost that is estimated or actually spent during the construction period of the project. Project cost management refers to the comprehensive application of management, economics, etc., and a series of processes such as forecasting, planning, controlling, and analyzing the cost of the entire project ${ }^{[1]}$. By implementing dynamic management and control of cost in highway projects, it is conducive to complete the content of the highway project within the specified time and avoid delays. The dynamic management of cost includes the management of manpower, material resources and materials in the project development process. Through scientific management, the orderly operation of the project can be ensured, and the cost of the road construction can also be reduced. Funding is an element in the whole process of highway construction. Through dynamic project cost management, the use of funds can be predicted, monitored and analyzed to avoid waste, which increases profits to a certain extent. In addition, the dynamic management and control of highway cost will involve all aspects of highway construction, such as 
manpower, material resources, and financial resources. When these important elements are controlled, the quality of the highway is also guaranteed.

\section{Analysis of the main factors affecting the cost of highway engineering}

Highway engineering is the infrastructure construction of our country, and it has played a very important role in the economic development of various regions. In the process of highway construction, project cost is an important factor that cannot be ignored. The following describes several factors that affect project cost.

\subsection{Changes in highway engineering}

In the process of highway engineering construction, there will be engineering changes, which means that within the scope of the contract, the contractor makes changes in accordance with the documents issued by the supervisor and the change instructions, including changes in the amount of work in the contract, adding or subtracting work content, or adding content outside the contract. The reason for the changes in the cost of highway projects is closely related to insufficient surveying efforts and inaccurate data acquisition. Of course, it may also be related to unforeseen circumstances during the construction process. Once there is a change in the highway project, it will have a direct impact on the cost of the highway project.

\subsection{The impact of construction materials and equipment}

Many mechanical equipment and raw materials are used in the construction of the highway. These machinery and equipment are usually relatively special, such as the two-liner trolley, which has a relatively high technological content. Whether it is directly purchased or rented, the cost is not negligible. If there is an accident in these construction equipment's during the construction process, for example, it cannot be used normally, it will affect the entire construction schedule of the highway, which will inevitably affect the cost of the entire project. In addition, raw materials are a very important part of the construction process, which will determine the quality of highway projects and account for most of the cost of railway construction. If the procurement of materials is not well controlled during the entire construction process, poor quality materials are purchased and rework is caused, or the price of the purchased materials is higher, the cost of the project will increase.

\subsection{The influence of design and construction}

The design link of highway construction is a means to effectively control the construction cost. Therefore, it is usually necessary to determine the section, geology and parameters of the highway before designing, design a reasonable construction plan, and select appropriate construction materials. However, if the designers did not design the highway project based on the actual situation in the design phase, the later organization will inevitably appear to be inadequate, which will affect the cost of the highway project. What's more, there are many influencing factors in the construction process. If the construction technology is not in place, it will affect the quality and cause later rework. The construction efficiency is not well controlled during the construction process, which will result in not being completed within the specified construction period. Failure to do a good job of financial control in the construction process will result in a waste of funds. All these will have an impact on the cost of highway projects.

\section{Strategies for dynamic management and control of highway engineering cost}

Through the analysis of the main factors affecting the cost of highway engineering, it can be seen that in the management of highway engineering cost, changes in highway engineering, design factors, construction factors, construction materials and equipment, etc., will affect the cost of highways. Therefore, it is 
necessary to implement dynamic control of these contents in order to reduce the capital loss caused by uncertainty and improve the efficiency of highway engineering management. The following specifically analyzes the strategies implemented by dynamic management in the project cost from four perspectives, namely the design phase, the bidding phase, the construction phase, and the completion phase.

\subsection{Application of dynamic management of project cost in the design phase}

In highway engineering, engineering design is the prerequisite for all projects, and it will affect the reasonable arrangements of manpower, material resources and financial resources for later construction. Therefore, it is necessary to integrate the dynamic management of the project cost reasonably in the design phase.

(1) Specify design standards to reduce errors in the implementation process. Pay attention to the cost control of the design link, focus on the expected goal in the design, and rationally incorporate new methods and technologies. The parameters involved must be tested and scientifically demonstrated, so as to reduce the economic benefits of the entire project cost.

(2) Carry out standardized highway engineering design management. The construction company can set up a special department to control the quality of highway construction, and compare the error between the established result and the actual result according to the unified highway index, so as to ensure the reasonable operation of the entire highway construction.

(3) Implement quota design. From the beginning of construction, it is necessary to analyze funds and set quotas reasonably. In short, incorporating dynamic engineering cost management in the design stage can better avoid a series of excess problems caused by insufficient accuracy in the later phase [2].

\subsection{Application of dynamic management of project cost in the bidding phase}

The project cost in the bidding phase can not only realize the preliminary estimate in the design process, but also effectively control the scale and quality of the later project development. The specific dynamic management is reflected in the following points. The first point is to analyze the relevant factors of the project cost on the premise of fully collating the content of the entire highway project to ensure the accuracy of the entire tender document. Secondly, before the start of the bidding activities, it is necessary to organize the bidding documents to ensure their quality. Thirdly, after the start of the bidding activities, it is necessary to screen and filter the construction plans and materials provided by some construction units, analyze the bidding documents among them, and select high-quality bidding companies and plans. In the whole process, a stricter bidding management system must be established to clarify the person in charge of each project in bidding and bidding management and their responsibilities, so as to avoid bribery and other situations. Once such a situation is discovered, severe penalties will be imposed. Through such a strict dynamic management of the project cost, the smooth operation of the bidding phase can be guaranteed.

\subsection{Application of dynamic management of project cost in the construction phase}

In the entire highway project, the construction phase is a very important part, the effect of the construction phase will directly affect the quality of the entire project and the final cost. However, the manpower and technology involved in the construction phase are relatively large, so it will also be affected by various factors. At this phase, reasonable cost control must be done to ensure the quality of the entire construction process.

(1) Construction materials are a very important part of the entire highway construction process. The price and quality of construction materials will have a great impact on the entire highway construction. In the current building materials market, prices are constantly changing. Therefore, as 
a highway construction purchaser, it is necessary to measure the quality and price of materials to avoid low purchase prices and serious material problems. At the same time, we should not pursue materials too much and ignore the cost, but should be reasonably controlled.

(2) To avoid a series of cost changes and quality problems caused by man-made problems. Therefore, it is necessary to manage the construction contract during the entire construction process, sign labor contracts with the constructors in accordance with corresponding laws and regulations, and timely stipulate various changes, so that man-made changes can be effectively avoided.

(3) The management of construction technology should be strengthened. Construction technology will not only affect the construction schedule, but also have a direct impact on the quality of the highway. Therefore, it is necessary for the construction staff to review the design drawings in advance, and formulate the construction process and technology in advance according to the design to avoid technical inconsistencies. If we need to change the project temporarily, we need to submit it in accordance with the regulations, and ensure the consistency of the highway design and before and after the construction as much as possible ${ }^{[3]}$.

\subsection{Application of dynamic management of project cost at the completion phase}

Project settlement is the final link of highway engineering, which will also affect the cost of the entire project, so reasonable control is required. Firstly, after the completion of the project, it is necessary to sort out and analyze a series of designs and data during the construction process, so that various costs can be calculated with justification. Secondly, accurately calculate the engineering quantity, check the engineering quantity on the list in detail and comprehensively, and improve the accuracy of the data. In addition, review the measurement and payment work, carefully and accurately measure, if problems are found, they must be resolved in time to improve accuracy. When calculating the final payment, each period should not be accumulated, and the quantity of the entire project should be fully calculated starting from the as-built drawings. Finally, a ledger is established to record and check the changes in various projects in the construction process in a timely manner to ensure the accuracy of the entire record.

\section{Conclusion}

All in all, the highway project itself involves manpower, material resources and capital. To ensure the rational operation of the entire project, it is necessary to implement dynamic management of the cost and reasonably control it. Specifically, in the management and control, comprehensive management should be carried out in the design phase, bidding phase, construction phase, and completion phase, so as to reduce the cost of highway engineering in the construction process, ensure quality, and improve efficiency.

\section{Disclosure statement}

The author declares no conflict of interest.

\section{References}

[1] Zheng W, 2021, Research on the Whole Process Cost Management in Highway Engineering Projects. Engineering Construction and Design, (06): 200-202.

[2] Duan X, 2021, Research on Factors Influencing Highway Cost and Effective Cost Control Measures. China Equipment Engineering, (08): 227-228.

[3] Xie Y, 2021, Problems in the Tendering and Bidding of Highway Projects. Sichuan Cement, (03): 222-223. 